\title{
A description of the bite mark identification ability of alginate impression on students at Dental Faculty of Prof. Dr. Moestopo University
}

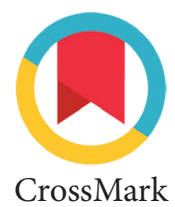

\author{
Pricillia P. Sianita*
}

\section{Abstract}

Objective: Trying to explain the extent to which our students are able to identify, through dentition, a bite mark injury.

Material and Methods: As many as 30 students in the Dental Faculty of Prof. Dr. Moestopo University were involved in this study to demonstrated their ability to identify traces left behind from the experimental bite mark of alginate impression. The data obtained will be tabulated to explain the subject's ability to identify the bite mark injury.

Results: The data showed that the identification ability of seniorsemester students is lower than that of junior-semester students.
The identification ability of the student decreases with the time elapsed since when the related lesson (dental anatomy) is given. Dental anatomy was given in the first semester and the lowest score of identification ability indeed achieved by subjects in the highest semester (senior students at semester eight involved in this program study).

Conclusion: In this case, it is evident that repetition is an important factor in a learning process, and therefore, it is necessary to think of a way to do it appropriately in the curriculum of the dentist education program in our faculty.
Department of Orthodontics, Faculty of Dentistry, Prof. DR.Moestopo University, Indonesia

\section{*Corresponding to:}

Pricillia P. Sianita, Department of Orthodontics, Faculty of Dentistry, Prof.DR.Moestopo University, Indonesia

ppsianita@gmail.com

Received: 1 July 2018

Revised: 3 July 2018

Accepted: 23 July 2018

Available online 1 August 2018

Keywords: Forensic odontology, Bite mark, Tooth identification

Cite this Article: Sianita PP. 2018. A description of the bite mark identification ability of alginate impression on students at Dental Faculty of Prof. Dr. Moestopo University. Journal of Dentomaxillofacial Science 3(2): 96-103. D0l: 10.15562/jdmfs.v3i2.759

\section{Introduction}

Indonesia, which lies between the unions of three major tectonic plates, namely Eurasian, IndoAustralian and Mediterranean, along with demographic conditions consisting of various ethnicities with different cultural backgrounds and religions make it very unique. On the other hand, Indonesia is also known as a disaster supermarket because almost all kinds of disasters have occurred in this country, such as tsunamis, landslides, disease outbreaks, floods and volcanic eruptions, to the fall of aircraft involving many victims or mass casualties. In a disaster involving large numbers of victims, identification is an important aspect that must take time into account because the process of decomposition in the victim's body requires a reliable action to execute the identification process.

Teeth, also known as dental fingerprints, are one out of three components in primary identification that allows the victim to be identified quickly, so that it can returned immediately to the family where he belongs. As the strongest part of the human body, teeth can stand facing high explosion and are rarely damaged by such incidents. ${ }^{1-3}$ Consequently, teeth are likely to be found in mass fatality disaster, where the other means of identification are destroyed. Teeth arrangement in different oral cavities is unique in every person and each tooth has a set of unique characteristics that formed the important foundation of dental identification. ${ }^{3-5}$ Moreover, identification means determination of individuality of a person and dentist is one of many kind of experts who can make contributions towards solving identity. As we all know, primary identification in Forensic Odontology consists of three things that are fingerprints, DNA and dental medical records. It is in the dental medical record that there is a major role of dentist who can help or even possibly harm his patient who by chance becomes a victim in a disaster. ${ }^{6,7}$

The victim of a disaster or a crime can be in the form of bite injury/bite mark. A bite mark is a mark resulted from teeth either alone or in the combination with other oral structures. ${ }^{8}$ The bite lesions can be both found in victims and perpetrators as a result of self defence or victim resistance against the perpetrators. ${ }^{9}$ So criminal may lie through his teeth although the teeth themselves cannot lie. ${ }^{10,11}$ Every bite mark accompanied by traces of anterior teeth as a result of a physical alteration caused by the contact of teeth. ${ }^{12,13}$ In this case, the process of identification through the teeth, both in the form of bite mark injury and dental data written in the dental medical record is a skill that should be owned by the dentist, especially in Indonesia, because it 
relates to the education they have received (dental anatomy) and their active participation as an expert needed. Besides, with proper analysis, a bite mark can prove the involvement of a particular person or persons in a particular crime. . $^{11,13,14}$

A dental medical record is a written data on a patient card containing complete and accurate information about a patient's identity, diagnosis, disease course, medical treatment process, and dental medical action and documentation of result of examination which is also valid legal evidence figure $1 .{ }^{15,16}$ Dental data in a medical record is a dentist's responsibility to his patient; that is, as evidence of dental care that has been performed or given to the patient. If, for some reasons, the patient requires a medical record of this tooth in the future, then a copy of the medical record data can be given, while the original data must remain with the dentist for future reference.

The time limit for this medical records storage, according to the Regulation of the Minister of Health of the Republic of Indonesia, shall be the maximum of five years and the dental medical records shall be retained for at least 25 years. ${ }^{15}$ Thus, a medical record can help the patient who owned the data in it when it contains complete information about the dental health of the patient that involves the role of the dentist providing the dental care or dental treatment. Therefore, the data in the medical record should always be updated according to the most recent type of dental health care the patient receives.

In this study, the identification ability of student in the Faculty of Dentistry, Prof. Dr. Moestopo University was tested to determine the extent to which the absorption of science Dental Anatomy that has been obtained can be applied in relation to the process of identifying bite marks.

\section{Material and Methods}

A total of 30 students from the Dental degree program, which is divided into two groups based on the level of semester. The junior group from the second semester consisted of fifteen students and the senior group from the seventh semester also with fifteen students were included in this study. All subjects in this study had an A grade for Dental Anatomy as per the inclusion criteria. In Indonesia, a title of dentist is awarded to students who have completed academic and clinical/profession programs.

The identification of a bite mark is done by comparing antemortem data and post mortem data. The antemortem data is data from someone made during his lifetime. The recording of antemortem data can be done simply, visually including clothing, jewellery or scientifically covering fingerprint, medical, serological and also odontologic data/dental conditions in the medical record (odontogram). ${ }^{16}$ Post mortem data is data from someone made after death (victim's data). Post mortem data recording can be done visually, through photographs or dental impression of double impression or alginate material that have been made into models with gypsum materials.

Alginate impression material is an irreversible impression material that has some good properties, and hence, widely used in the world of dentistry. Some of these properties include ease of manipulation, cheap cost, do not require special equipment, and are quite acceptable for the patient. ${ }^{17-20}$ Specifically for this research, some properties needed in alginate impression materials are the quality of flexibility which makes it easy to remove without tearing when released in hardened conditions but is still flexible. Furthermore, as the detail quality and hardening/setting time is good enough, not toxic and not irritating, as well as being quite cheap in terms of price, making this alginate the impression material used in this study. ${ }^{21-25}$

The antemortem data in this study was obtained from 10 students attending the professional program in our dental education. Dental education in Indonesia consist of academic program and professional program, this two programs must be completed before they are registered as dentist and allowed to practice as a dentist professionally. In each of these students, data was created in the form of intraoral and profiles photographs figure 2, as well as the model of the teeth and the data of the incisor's area resulting from the tracing on the modelling wax or transparent paper figure 3. To obtain post-mortem data, each of the same students was required to make an experimental bite mark figure $4 \mathrm{~A}$ and $4 \mathrm{~B}$. By using alginate impression material and dental gypsum, the bite mark was then made into a working model figure 5. The next step to be taken is making a tracing of the bite mark on the working model with a transparent acetate paper to get a post-mortem data figure 6. Most of the comparative methods performed in the bite marks analysis are done by first making overlays. In this case, the overlay can be made from the working model. In producing this overlay, hand tracing is one of several methods that can be used to generate overlays. ${ }^{26}$

After obtaining antemortem and post-mortem data, the 10 pairs of data were randomly arranged or prepared for identification by 30 research subjects. The identification process done by the research subjects was to match the antemortem and 
post-mortem data within 30 minutes in phase 1 and repeated for a longer period of time, 60 minutes in phase 2 figure 7.

\section{Results}

In the first phase of the identification/matching process, the time given to the research subjects to complete the task is 30 minutes and the results obtained can be seen in table 1 and table 2 . Furthermore, the subjects were given a 30 minute break before entering the second phase of identification process. In the second phase of identification, the time given to complete the task is 60 minutes and the results obtained can be seen in table 3 and table 4.

Table 1 shows that junior students can identify very well, as most of the cases can be correctly identified. Only two subjects in this group gave the lowest result, identifying true for only half of the cases. Different things are shown by a group of senior students. In this group, the correctly identified data are generally less than half of the cases. Table 2 even shows two research subjects which yielded only one true identification and one subject that produced the highest correct number of identifications in this group, which is only four and still less than half the number of cases. In this senior group, most are less successful in identifying true against the ten (10) prepared cases.

In the second phase of identification process, with a longer time span of 60 minutes, both groups of subjects showed an increase in the number of cases identified correctly.

The results obtained at phase two can be seen in table 3 and table 4 below. The number of cases identified correctly showed an increase in both groups, but the junior group still showed higher identification ability compared to the senior group.

The identification process in phase two with longer time ( 60 minutes) gives better results to the junior group. Three research subjects successfully identified 10 cases correctly and more than half of the research subjects, eight people who quite successfully identified the case correctly and had only one error/mismatch. Overall, the research subjects in the junior group showed encouraging results because in addition to showing an increase in the number of cases identified correctly, to all members in this group, none resulted in correct identification of less than half the number of cases. An illustration of the increase in the number of correctly identified cases is also true in the group of senior research subjects in the second phase that had a longer duration of 60 minutes table 4 . However, the results shown are still less satisfactory, as only two research subjects successfully identified more than half of their cases (six) and another two research subjects identified half of their cases (five). Despite the improvements in this group of senior research subjects, the results shown in table 4 show that most (eleven) of the subjects in this group were less successful in correctly identifying the prepared cases. The value obtained is even less than half the number of cases. Extending the working time has not been fully able to assist the identification ability of the subjects in this group.

\section{Discussion}

In forensic dentistry, dental identification come up in two different methods. The first one is a method called comparative identification. This method is used to establish, in a high degree of certainty, that the remains found in victims and a person recorded in antemortem data, including the dental records are the same individual. The second one is for cases where the antemortem data is not available while the identification team has no clues to the possible identity. In such a case, the forensic dentist completes the post-mortem data in order to identify characteristics of the individual likely to narrow the search for the antemortem materials. The primary concept in forensic dental identification is to compare post-mortem dental remains with antemortem records, including dental records, study or

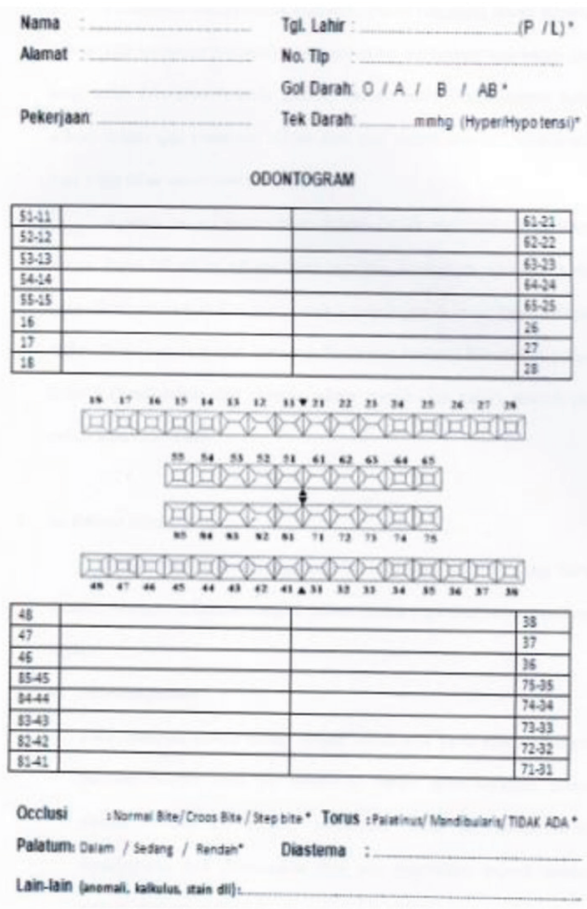

Figure 1 Example of medical record data to be made by the dentist as his responsibility to the patient 


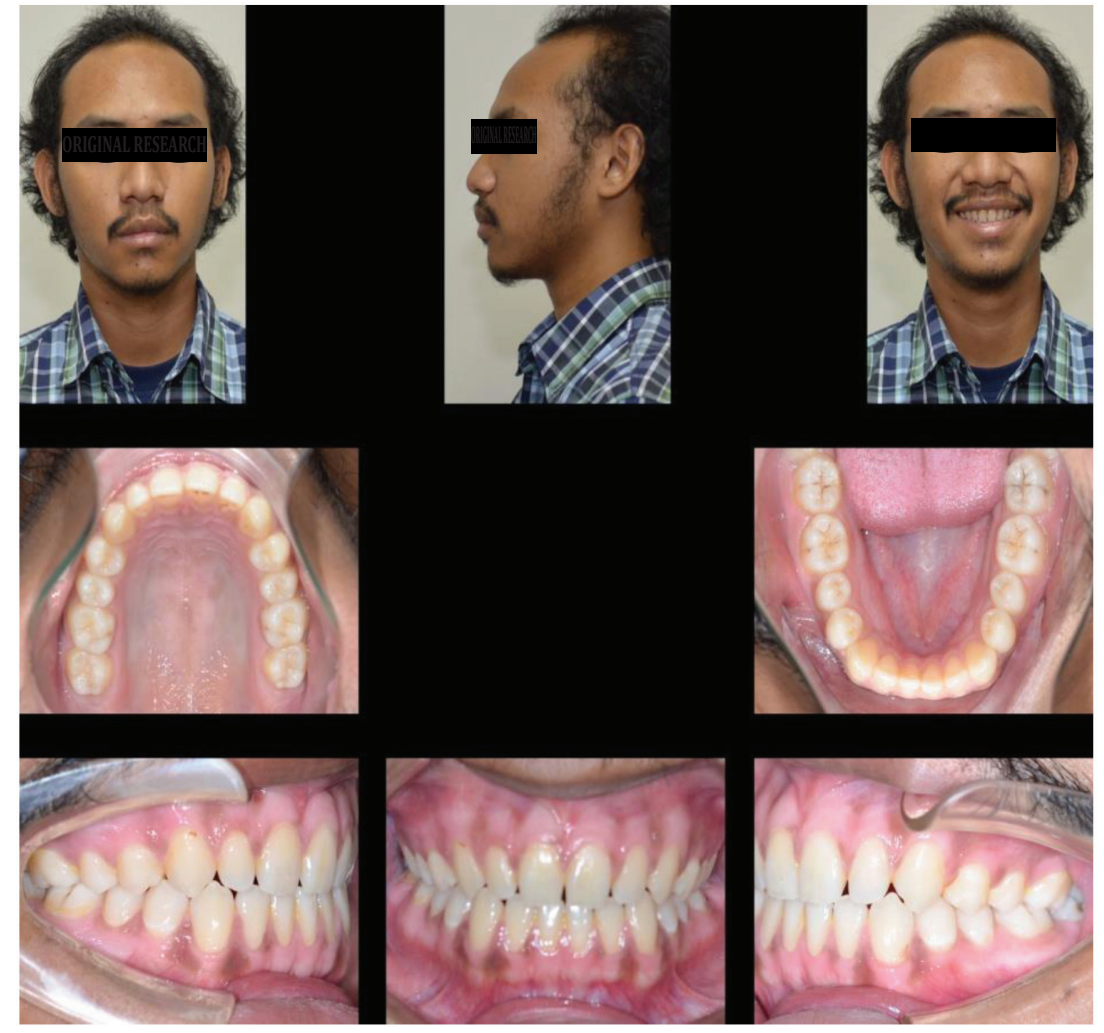

Figure 2 Photographs of patient's profile and intraoral were made to obtain antemortem data.
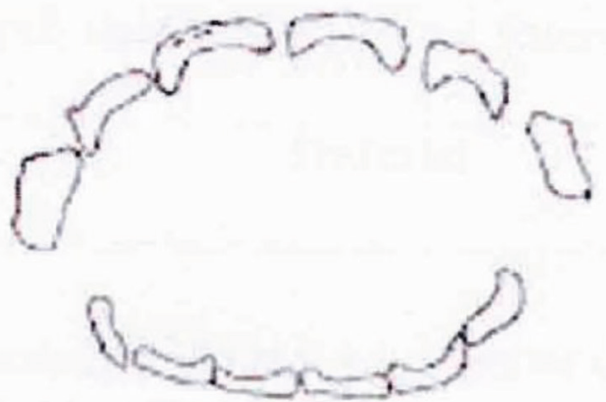

Figure 3 The outline of anatomical bite marks traced in the incisor region of the maxillary and mandibular anterior teeth that assist the research subjects in the identification process
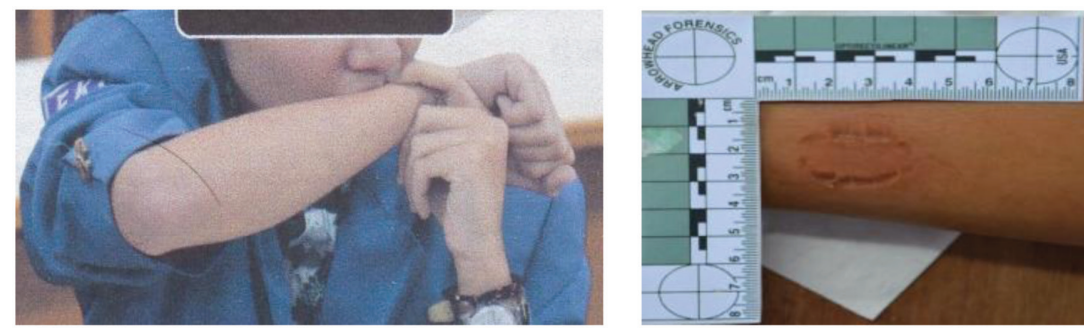

Figure 4

A. The process of making an experimental bite mark (antemortem) and $\mathrm{B}$. The resulted bite mark was photographed along with a no. 2 of American Board of Forensic Odontology (ABFO) ruler.

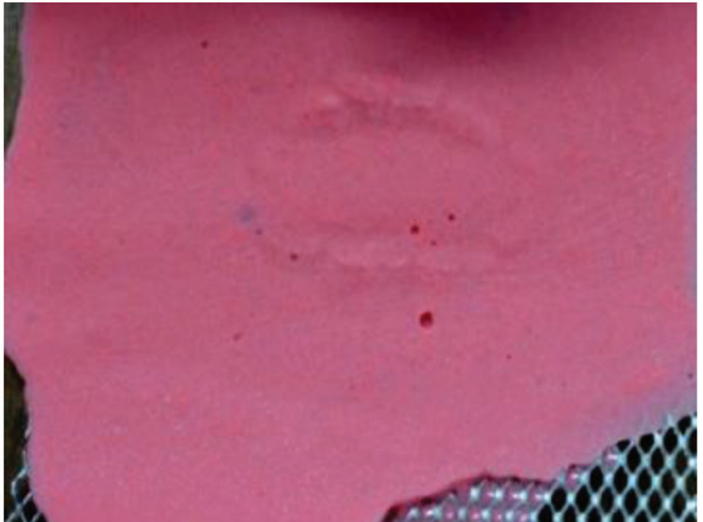

Figure 5 Alginate impression of experimental bite mark was made and used as post-mortem data.

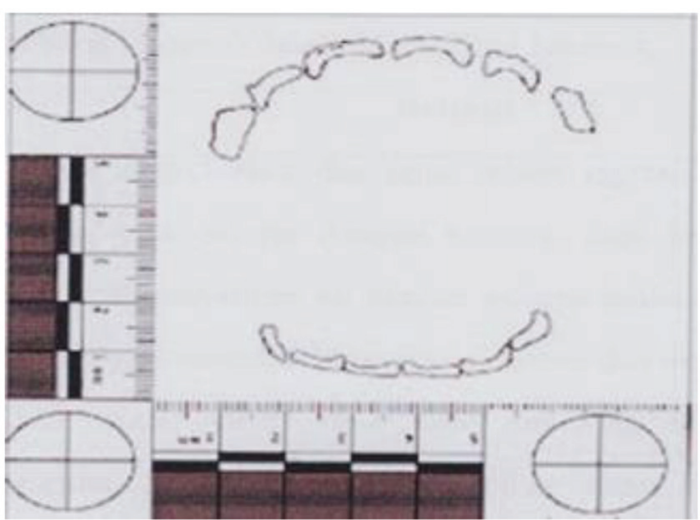

Figure 6 Post-mortem data of bite mark was traced on acetate paper prior to being photographed with no. 2 of ABFO ruler

working models, and all kinds of radiographs made during his life (before death) to confirm identity. ${ }^{6}$

An identification process that involves the process of comparing antemortem data and postmortem bite mark data can be done by several methods, one of which is used quite often in comparing the post-mortem data with, antemortem data which are dental model tracing results, using acetate transparent paper to show the outline of the incisor area of six upper and lower anterior teeth. ${ }^{7,26,27}$ In this study, the prepared cases as post-mortem data was an experimental bite mark and the research subjects were asked to identify or process matching data with antemortem data that had also been prepared. The time given to the research subjects to complete the task is 30 minutes (phase one) and 60 minutes (phase two) with a 30 minute pause time.

Clearly indicate that achievement of senior level in the education process is not followed by mastery of material that has been obtained, especially for related subjects such as dental anatomy that has 

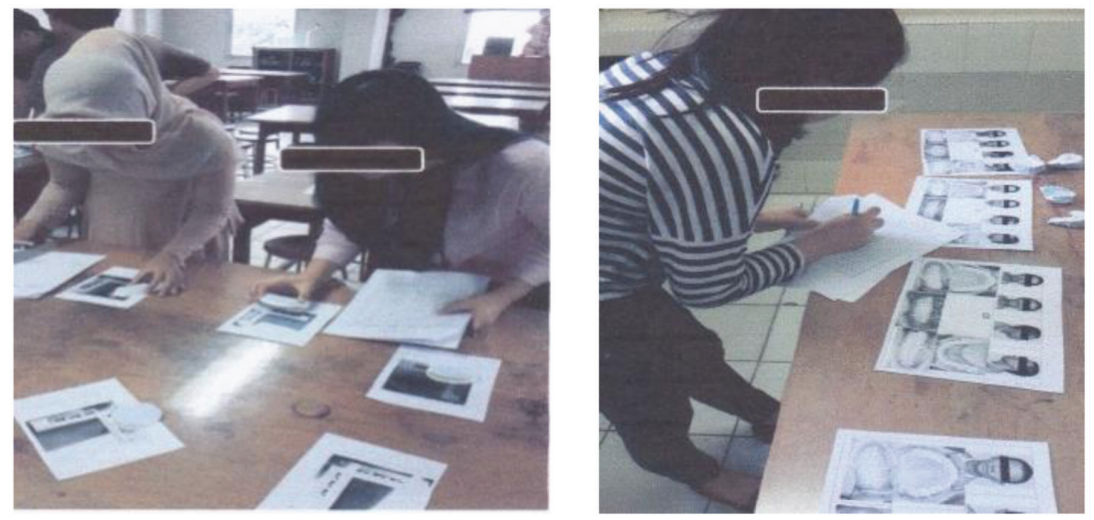

Figure 7 Research subjects work on randomly arranged antemortem and post-mortem data for identification or matching process.

\section{Table 1 Results of identification of junior subjects in the first phase-30 minutes}

\begin{tabular}{lcc}
\hline Subject & Identificationante and post-mortem \\
\hline Junior & match & mismatch \\
\hline 1 & 6 & 4 \\
2 & 7 & 3 \\
3 & 6 & 4 \\
4 & 5 & 5 \\
5 & 6 & 4 \\
6 & 7 & 3 \\
7 & 7 & 3 \\
8 & 6 & 4 \\
9 & 7 & 3 \\
10 & 5 & 5 \\
11 & 7 & 3 \\
12 & 7 & 3 \\
13 & 6 & 4 \\
14 & 6 & 4 \\
15 & 8 & 2 \\
\hline
\end{tabular}

been given in the first semester. The opposite is actually seen in the junior level group. In this group, the mastery of related materials was followed by satisfactory success in completing matching tasks in this study. The success rate is seen to be consistent in the two-time span of matching implementation. The added time given in the second phase proved to be quite useful in completing the identification process in the junior group rather than the senior group, which was seen in the increasing number of correct identified cases. Therefore, it was assumed that time is not a major problem in the success of this identification process. The problem that exists in the researcher's view is that the ability to retain or store the material that has been taught is much more important in this regard. An understanding based on a proper understanding of a thing will not disappear easily, so it should happen to a group of senior students. Related to this, it is also clear that achieving a higher (semester) level does not guarantee a better understanding of the material at the previous level. It is possible that the success of passing the exam phase to enter the higher level/semester is passed by the minimum quality required or even accidentally.

The facts obtained in this study, need to be treated wisely and in the view of researcher, some things need to be considered by the parties related to the world of dental education, namely the determination of the passing grade especially for the basic courses that are needed in the future. Looking for the right pattern in conducting exams that are able to demonstrate the correct level of mastery of the material, not by memorizing, but by reasoning because of a good understanding of something, so the examination can actually sort out those who are really competent from the less or incompetent. The examination should cover not just theory but practice which is more objective in scoring their understanding about the subject. This becomes important when we recognize that good mastery or understanding, especially in dental anatomy, is not only important for identification in the field of forensic odontology, but also in other dental fields, such as conservation and rehabilitation that require it for success in contour restoration of anatomy of a tooth for aesthetic reasons, function, and also health. Therefore, it is necessary to get the attention or consideration of those who are involved in education or the curriculum team in education in this field to obtain better quality results. If it says that learning involves a process of repetition, it is necessary to think of a way to always present a material in a higher level in the learning process. In this way, it is expected that the material can be embedded in more depth and better understood by the students in the education process.

One thing that is both comforting and perhaps promising about the findings or results of this study in relation to the important role of dentists in the process of dental identification is that the subjects in the sample of this research data have good dentition or have almost no fillings and various dental care characteristics, such as restoration, tooth malposition, crown and bridge etc. While in the process of identification based on comparative methods, conditions with variations in more complex characteristics will be more advantageous because it has a uniqueness that will ultimately facilitate the process of comparison and hence also identification. Thus, results 
Table 2 Results of identification of senior subjects in the first phase - $\mathbf{3 0}$ minutes

\begin{tabular}{lcc}
\hline Subject & \multicolumn{1}{c}{ Identification ante \& post-mortem } \\
\hline senior & match & mismatch \\
\hline 1 & 2 & 8 \\
2 & 2 & 8 \\
3 & 1 & 9 \\
4 & 2 & 8 \\
5 & 3 & 7 \\
6 & 2 & 8 \\
7 & 1 & 9 \\
8 & 2 & 8 \\
9 & 2 & 8 \\
10 & 2 & 8 \\
11 & 3 & 7 \\
12 & 4 & 6 \\
13 & 2 & 8 \\
14 & 2 & 8 \\
15 & 2 & 8 \\
\hline & &
\end{tabular}

Table 3 Results of identification of junior subjects in the second phase- 60 minutes

\begin{tabular}{lcc}
\hline Subject & \multicolumn{1}{c}{ Identificationante \& post-mortem } \\
\hline junior & match & mismatch \\
\hline 1 & 8 & 2 \\
2 & 9 & 1 \\
3 & 7 & 3 \\
4 & 9 & 1 \\
5 & 7 & 3 \\
6 & 10 & 0 \\
7 & 9 & 1 \\
8 & 7 & 3 \\
9 & 9 & 1 \\
10 & 9 & 1 \\
11 & 9 & 1 \\
12 & 10 & 0 \\
13 & 9 & 1 \\
14 & 10 & 0 \\
15 & 9 & 1 \\
\hline
\end{tabular}

that are less encouraging in this study may also be influenced by the lack of unique characteristics of various dental treatments as well as the malposition of teeth present in the antemortem data. Another factor that may have an effect on this less encouraging research results is due to the inadequacy of the bite trace model being reproduced. In these experimental bite marks, the anterior teeth pressure traces caused by the application of direct pressure from the incisal edges of subject's anterior teeth are less realistic and quickly fade during the impression making process to get the working model. This is because, in experimental bite marks, the subjects do so not for the purpose of inflicting injuries, but only the traces of teeth without having to cause injury/open wounds. 
Table 4 Results of identification of senior subjects in the second phase - 60 minutes

\begin{tabular}{lcc}
\hline Subject & Identificationante \& post-mortem & \\
\hline senior & match & mismatch \\
\hline 1 & 4 & 6 \\
2 & 6 & 4 \\
3 & 3 & 7 \\
4 & 4 & 6 \\
5 & 5 & 5 \\
6 & 4 & 6 \\
7 & 4 & 6 \\
8 & 3 & 7 \\
9 & 6 & 4 \\
10 & 4 & 6 \\
11 & 3 & 7 \\
12 & 4 & 6 \\
13 & 4 & 6 \\
14 & 3 & 7 \\
15 & 5 & 5 \\
& & 6
\end{tabular}

\section{Conclusion}

The results obtained show that the level of ability or mastery of a material, especially dental anatomy is not aligned with the level of semester that has been taken by students in the Faculty of Dentistry Prof. Dr. Moestopo University as evidenced in the group of students who were subjects in this study. The junior group of students proved more successful in identifying correctly than the senior group of students so that it can be said that the identification ability is not in line with the level of semester that students have passed, but with the level or quality of understanding that the student has successfully in his education process. The results of this study also indicate that to be able to participate in the process of identification through the teeth, real training, and continuous work experience is required in analyzing a bite mark.

\section{Acknowledgment}

The author would like to express sincere thanks to all students of the Faculty of Dentistry, Prof. Dr. Moestopo University for providing active participation during this research process.

\section{Conflict of Interest}

The author reports no conflict of interest.

\section{References}

1. Singh B. Palatal rugae-a finger print of oral cavity. Research \& Reviews: J Dent Sci 2015;3: 1-3.

2. Shaik K. Are tooth prints a hard tissue equivalence of finger print in mass disaster: a rationalized review. J Pharm Bioallied Sci 2017;9(suppl 1): s29-s33.

3. Christopher V. Can dead man tooth do tell tales? tooth prints in forensic identification. J Forensic Dent Sci 2017;9: 47.

4. Sugunakar RGS. Ameloglyphics can it aid in forensic identification. Indian J Dent Adv 2014;6: 1669-1673.

5. Manjunath K, Sivapathasundharam B. Analysis of enamel rod end pattern at different levels of enamel and its significance in ameloglyphics. J Forensic Res 2014;5: 235.

6. Krishan K, Karchan T, Garg AK. Dental evidence in forensic identification an overview, methodology and present status. Open Dent J 2015;9: 250-256.

7. Pretty IA, Sweet D. A look at Forensic dentistry-part 1: The role of teeth in the determination of human identity. Br Dent J 2001;7: 190

8. Macdonald DG. Bite mark recognition and interpretation. J Forensic Sci Soc 1974;14: 229-233.

9. Verma AK. The role of dental expert in forensic odontology. Natl J Maxillofac Surg 2014;15: 2-4.

10. Furness J. A New Method for the identification of teeth marks in cases of assault and homicide. Br Dent J 1968;124: 261-267.

11. Kaur S. Analysis and identification of bite marks in forensic casework. Oral Health Dent Manag 2013;12: 500.

12. MacDonald DG. Bite mark recognition and interpretation. J Forensic Sci Soc 1974;14: 229-233.

13. Sweet D, Pretty IA. A look at forensic dentistry-part 2: teeth as a weapons of violence-identification of bite mark perpetrators. Br Dent J 2001;190: 415-418.

14. Layton JJ. Identification from a bite mark in cheese. J Forensic Sci Soc 1966;6: 76-80.

15. Hamrun N, Rachman SA. Measuring sodium alginate content of brown algae species padina sp. as the basic matter for making dental impression material (irreversible 
hydrocolloid impression material). J Dentomaxillofac Sci 2016;1: 129-133.

16. Iqony RA, Kristiani S, Budi AT. Electronic dental record data base as a storage media of antemortem data based on website. Dent Forensic J 2016;3: 12-23.

17. Nandini V, Verkatesh KV, Nair CK. Alginate impression: a practical perspective. J Conserv Dent 2008;11: 37-41.

18. Rubel BS. Impression materials: a comparative review of impression materials mostly used in restorative dentistry. Den Clin North Am 2007;51: 629-642.

19. Murata H. Physical properties and compatibility with dental stones of current alginate impression materials. J Oral Rehab 2004;31: 1115-1122.

20. Giordano R. Impression materials: basic properties. Gen Dent 2004;48: 510-516.

21. Wadhwa SS. The effect of pouring time on the dimensional accuracy of cast made from different irreversible hydrocolloid impression materials. Contemp Clin Dent 2013;4: 313-318

22. Imbery TA. Accuracy and dimensional stability of extendedpour and conventional alginate impression materials. J Am Dent Assoc 2010;141: 32-39.
23. Rudd KD, Morrow RM, Strunk RR. Accurate alginate impression. J Prosthet Dent 1969;22: 294-300.

24. Fairchild JM. Versatile uses for alginate impression material. J Prosthet Dent 1974;31: 266-269.

25. Walker MP. Dimensional change over time of extended storage alginate impression materials. Angle Orthod 2010;80: 1110-1115.

26. Sweet D, Bowers CM. Accuracy of bite mark overlays: a comparison of five common methods to produce exemplars from a suspect's dentition. J Forensic Sci 1998;43: 362-367.

27. Verma AK, Kumar S, Bhattacharya S. Identification of a person with the help of bite mark analysis. J Oral Biol \& Craniofacial Res 2013;3: 88-91.

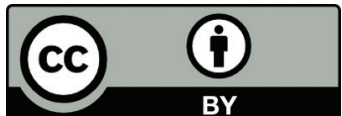

This work is licensed under a Creative Commons Attribution 